\title{
Folate-Functionalized Mesoporous Silica Nanoparticles as a Liver Tumor-Targeted Drug Delivery System to Improve the Antitumor Effect of Paclitaxel
}

\author{
Xiaoyan Xu, Chao Wu, Andi Bai, Xuan Liu, Huiling Lv, and Ying Liu \\ Pharmacy School, Jinzhou Medical University, 40 Songpo Road, Linghe District, Jinzhou, Liaoning Province 121000, China \\ Correspondence should be addressed to Chao Wu; zifengas123@163.com
}

Received 1 July 2017; Revised 12 September 2017; Accepted 28 September 2017; Published 31 October 2017

Academic Editor: Hassan Karimi-Maleh

Copyright (c) 2017 Xiaoyan Xu et al. This is an open access article distributed under the Creative Commons Attribution License, which permits unrestricted use, distribution, and reproduction in any medium, provided the original work is properly cited.

The aim of this study was to prepare and characterize an innovative hepatocellular carcinoma-targeted therapeutic drug delivery system based on folate-PEG-mesoporous silica nanoparticles (FA-PEG-MSNs) loaded with paclitaxel (PTX). In vitro cell experiments and an in vivo antitumor efficacy study demonstrated that FA-PEG-MSNs-PTX produced significantly higher tumor inhibition compared with pure PTX and mesoporous silica nanoparticles loaded with paclitaxel (MSNs-PTX). The biodistribution investigation of PTX in nude mice revealed that the FA-PEG-MSNs-PTX could accumulate in tumors. Folic acid functionalized MSNs resulted in a good targeting effect, confirming that FA-PEG-MSNs-PTX is a promising tumor-targeted drug delivery system for liver cancer chemotherapy.

\section{Introduction}

In recent years, the incidence of liver cancer has been rapidly increasing. According to one report, 782,000 liver cancer cases are diagnosed and 745,000 deaths are reported annually [1]. Because of low survival rates and poor prognosis, it has become the second most common cause of cancer death worldwide [2]. China has the highest number of cases of hepatocarcinoma [3]. Many potential antitumor drug candidates exhibit poor solubility in water and poor dissolution, which limits their absorption $[4,5]$. Conventional anticancer drugs can affect healthy tissues as well as tumors. Therefore, normal cells are destroyed, which results in undesirable side effects such as tissue damage, inflammation, or lesions [6-8]. In addition, multidrug resistance of cancer cells to anticancer drugs is also an acute problem in the treatment of cancer.

As a novel inorganic material, mesoporous silica is attracting wide attention. Mesoporous silica with good biocompatibility not only has many novel features, such as a large pore volume, tunable pore structure, controllable particle size, and good chemical and excellent physicochemical stability but can also be easily synthesized [9-12]. The nanosized particles can accumulate in the tumor region, which increases the concentration of anticancer drug there, resulting in a better antitumor effect [13-15]. In addition, mesoporous silica can be easily functionalized. Ligands for the overexpressed receptors in cancer cells, such as folic acid [16, 17], lactobionic acid [18], chitosan $[19,20]$, ferritin $[21,22]$, iodinated hyaluronic acid [23, 24], and antibody fragments [25-27], can be modified on the surface of the mesoporous silica, which can increase the tumor-targeting effect of the anticancer drugs, reduce the side effects of the chemotherapeutic drugs, and achieve accurately controlled therapy. Research by Lu's group has reported that camptothecin can be loaded into mesoporous silica nanoparticles in order to improve its solubility and the camptothecinloaded mesoporous silica nanoparticles exhibit significant tumor-suppression effects [28]. $\beta$-Cyclodextrin multifunctionalized magnetic mesoporous silica nanoparticles have been used to load doxorubicin into targeted cancer cells to reduce its toxicity [29]. In order to improve the solubility of cisplatin and achieve a tumor-targeted effect, Rajan et al. prepared chitosan multifunctionalized mesoporous silica nanoparticles as a carrier material [20].

In this study, we prepared FA-PEG-MSNs with a 100-nm particle size for use as a drug carrier. FA-PEG was conjugated 
to the surface of the MSNs to enable tumor targeting. It is well known that FA can specifically combine with folic receptors which are highly expressed in hepatocellular carcinoma cells [30]. Through in vitro and in vivo experiments, we examined whether FA-PEG-MSNs could increase the absorption of PTX and improve its antitumor effect.

\section{Materials and Methods}

2.1. Materials. Paclitaxel (PTX) was obtained from Xian Natural Field Bio-Technique Co., Ltd. (Xi'an, China) with $>99 \%$ purity. Folic acid, $\mathrm{NH}_{2}$-PEG-COOH (molecular weight $5 \mathrm{kDa}), \mathrm{N}$-hydroxysuccinimide (NHS), dicyclohexyl carbodiimide (DCC), 1-ethyl-3[3-dimethylaminopropyl] carbodiimide hydrochloride (EDC), cetyltrimethyl ammonium bromide (CTAB), tetraethyl orthosilicate (TEOS), sodium dodecyl sulfate (SDS), 3-aminopropyltriethoxysilane (APTES), pyridine butylparaben, dimethyl sulfoxide (DMSO), ammonia, ethanol, methanol, and hydroxypropyl methylcellulose (HPMC) were all obtained from Sinopharm Chemical Reagent Company, Ltd. (Shanghai, China) while thiazolyl blue tetrazolium bromide (MTT), Annexin V-FITC Apoptosis Detection Kits, and trypsin were supplied by Nanjing Jiancheng Bioengineering Institute (Nanjing, China).

\subsection{Preparation of $M S N s$ and FA-PEG-MSNs}

2.2.1. Preparation of MSNs. The MSNs were prepared using ethanol and water as the reaction medium and CTAB as a surfactant, according to previous reports [31]. Briefly, $0.5 \mathrm{~g}$ of CTAB was added to an emulsion system composed of $0.8 \mathrm{ml}$ of aqueous ammonia, $20 \mathrm{ml}$ of ethanol, and $70 \mathrm{ml}$ of $\mathrm{H}_{2} \mathrm{O}$. The mixture was vigorously stirred for $0.5 \mathrm{~h}$ at $25^{\circ} \mathrm{C}$, then $2.5 \mathrm{ml}$ of TEOS was dripped into the mixture. The system was then stirred at $400 \mathrm{rpm}$ for $4 \mathrm{~h}$ at $25^{\circ} \mathrm{C}$ and the obtained white precipitate was washed 3 times with water and dried in air at $60^{\circ} \mathrm{C}$ for $24 \mathrm{~h}$. Finally, the products were calcinated in air at $550^{\circ} \mathrm{C}$ for $5 \mathrm{~h}$.

2.2.2. Synthesis of FA-PEG and FA-PEG-MSNs. FA and $\mathrm{NH}_{2}-$ PEG-COOH were conjugated using the amido bond. In brief, FA (70.62 mg) was activated in DMSO by DCC (66.02 mg) and NHS $\left(36.82 \mathrm{mg}\right.$ ) for $12 \mathrm{~h}$ at $25^{\circ} \mathrm{C}$. The solution was adjusted to a basic $\mathrm{pH}$ using pyridine, and then $\mathrm{NH}_{2}$-PEG$\mathrm{COOH}$ was added to the system. After reacting for $4 \mathrm{~h}$, the mixture was dialyzed initially using DMSO for 2 days, followed by $\mathrm{H}_{2} \mathrm{O}$ for 3 days. The final product was lyophilized and its identity was confirmed by ${ }^{1} \mathrm{H}$ NMR spectroscopy in deuterated DMSO.

Five hundred milligrams of MSNs was suspended in of $50 \mathrm{ml}$ absolute ethanol and dispersed by ultrasonication for $10 \mathrm{~min}$. Then, $2 \mathrm{ml}$ of APTES was added to the suspension followed by refluxing at $77^{\circ} \mathrm{C}$ for $12 \mathrm{~h}$. The mixture was centrifuged and washed 3 times with ethanol, and the final product was dried in a vacuum to obtain ammoniated MSNs.

Next, $180 \mathrm{mg}$ of FA-PEG was coupled to the ammoniated MSNs using EDC and NHS as activation agents at $25^{\circ} \mathrm{C}$ for $12 \mathrm{~h}$. The mixture was dialyzed with pure water for 2 days and then lyophilized, and the identity of the FA-PEGMSNs was confirmed by Fourier transform infrared (FTIR) spectrometry (Bruker IFS 55, Switzerland).
2.3. Drug Loading of MSNs and FA-PEG-MSNs. PTX, which is poorly water soluble and used clinically as chemotherapy, was selected as the model drug. It was loaded into MSNs or FA-PEG-MSNs by the adsorption equilibrium method. Two hundred milligrams of MSNs or FA-PEG-MSNs was soaked in PTX chloroform solution $(60 \mathrm{mg} / \mathrm{ml})$ for $5 \mathrm{~h}$. The drug loading procedure took place at room temperature with protection from light. The supernatant was removed by centrifugation and then the drug-loaded sample was dried under vacuum in order to prevent any adverse effects from residual solvent. The loading capacity was determined by HPLC (L-2400, Hitachi, Japan).

2.4. Characterization of MSNs and FA-PEG-MSNs. The morphology and structure of MSNs and FA-PEG-MSNs were observed by scanning electron microscopy (SEM) (JEOL JSM-7001F, Japan) and transmission electron microscopy (TEM) (Tecnai G2F30, FEI, USA).

2.5. Differential Scanning Calorimetry Analysis (DSC) and $X$-Ray Diffraction Measurements (XRD). Pure PTX, MSNs, physical mixtures of PTX and MSNs (PPM), physical mixtures of PTX and FA-PEG-MSNs (PPFA), MSNs-PTX, and FA-PEG-MSNs-PTX were monitored by DSC and XRD to characterize the solid state of PTX. DSC analysis was carried out using a differential scanning calorimeter (DSC60, Shimadzu, Japan) with programmed heating at a rate of $10^{\circ} \mathrm{C} / \mathrm{min}$ from $30^{\circ} \mathrm{C}$ to $300^{\circ} \mathrm{C}$, under nitrogen at a constant flow rate of $150 \mathrm{ml} / \mathrm{min}$.

$\mathrm{XRD}$ was performed using an X-ray diffractometer (Rigaku Geigerflex XRD, Company, Japan, $30 \mathrm{kV}$ and $30 \mathrm{~m}$ A Philips) with $\mathrm{Cu}-\mathrm{K} \alpha$ radiation. The step size was $0.02^{\circ}$, the scan speed was $5^{\circ} / \mathrm{min}$, and the samples were analyzed over the $2 \theta$ range from $3^{\circ}$ to $60^{\circ}$.

2.6. In Vitro Drug Release Study. In vitro drug release studies were carried out in a dissolution apparatus (RC-8D, Tianjin Guoming Medical Equipment Company, Ltd.) using the paddle method as described in the Chinese Pharmacopoeia (2015). The dissolution medium was $900 \mathrm{ml}$ of phosphate buffered saline (PBS) with a $\mathrm{pH}$ of 6.8 . The temperature was $37 \pm 0.5^{\circ} \mathrm{C}$, and the paddle speed was $100 \mathrm{rpm}$. The loaded samples (equivalent to $0.7 \mathrm{mg}$ PTX) were added to the dissolution medium, and samples $(4 \mathrm{ml})$ were removed at predetermined intervals and then passed through a $0.22-\mu \mathrm{m}$ membrane filter. The PTX concentrations in the samples were determined by HPLC using an instrument equipped with an L-2400 ultraviolet absorbance detector and an L-2130 pump. An Agilent 5 TC-C ${ }_{18}$ column $(250 \times 4.6 \mathrm{~mm})$ was used for analysis and a mixture of acetonitrile and water $(50: 50, \mathrm{v} / \mathrm{v})$ was used as the mobile phase with a flow rate of $1.0 \mathrm{ml} / \mathrm{min}$. All of the experiments were repeated in triplicate.

\subsection{In Vitro Cell Assay}

2.7.1. Cell Line Propagation. Human liver cancer SMMC7721 cells were cultivated by standard in vitro cell expansion methods. Generally, culture was carried out in RPMI-1640 medium containing $10 \%$ fetal bovine serum, $1 \%$ penicillin, and $1 \%$ streptomycin with replacement with fresh medium at 2-day intervals. $0.25 \%$ Trypsin was used to digest the cells during cell passage. 
2.7.2. In Vitro Cytotoxicity Assay. To evaluate the in vitro cytotoxicity of MSNs-PTX and FA-PEG-MSNs-PTX on SMMC-7721 cells, an MTT assay was conducted. SMMC-7721 cells were seeded into 96-well plates at 5000 cells/well. After $24 \mathrm{~h}$ of culture, pure PTX, MSNs-PTX, or FA-PEG-MSNsPTX was suspended in culture medium and diluted to various concentrations $(500,250,100,50,10$, and $5 \mathrm{ng} / \mathrm{ml})$. Then, $100-\mu l$ samples of the diluted suspensions were added to the 96-well plates and the cells were exposed to the suspension for $48 \mathrm{~h}$ at $37^{\circ} \mathrm{C}$. To determine the biosafety of the MSNs and FA-PEG-MSNs, they were also suspended in culture medium, and suspensions with different concentrations (250, $120,60,30$, and $15 \mu \mathrm{g} / \mathrm{ml}$ ) were added to the 96 -well plates. The cells were incubated for $48 \mathrm{~h}$, and then $20 \mu \mathrm{l} /$ well of MTT ( $5 \mathrm{mg} / \mathrm{ml}$ ) solution was added to the 96 -well plates and cultured for a further $4 \mathrm{~h}$ in the dark. The supernatants were replaced with $150 \mu \mathrm{l}$ of DMSO to dissolve the bluish violet formazan crystals. After shaking for $10 \mathrm{~min}$ on a shaking incubator, cell viability was determined by the OD value, which is the absorption of the formazan product at a wavelength of $492 \mathrm{~nm}$ using a microplate reader (VERSAmax, Molecular Devices, Sunnyvale, CA, USA). The cell viability was calculated using the following formula:

$$
\text { Cell viability }=\frac{\mathrm{OD}_{t}}{\mathrm{OD}_{c}} \times 100 \% \text {, }
$$

where $\mathrm{OD}_{t}$ is the absorbance of the cells incubated with drug suspensions and the $\mathrm{OD}_{c}$ is the absorbance of the control.

2.7.3. Cell Uptake Assay. To obtain FITC fluorescence-labeled MSNs (FITC-MSNs) and FA-PEG-MSNs (FITC-FA-PEGMSNs), FITC was dissolved in $1 \mathrm{ml}$ of absolute alcohol and then $100 \mathrm{mg}$ of ammoniated MSNs or FA-PEG-MSNs was added to the solution. After $4 \mathrm{~h}$, the mixture was centrifuged, and then FITC-MSNs and FITC-FA-PEG-MSN were obtained by vacuum drying. SMMC-7721 hepatocellular carcinoma cells were seeded in a 12-well plate until $80 \%$ confluence. Then, the cells were treated with $20 \mu \mathrm{g} / \mathrm{ml}$ FITCMSNs or FITC-FA-PEG-MSNs and incubated for $0.5,1$, and $2 \mathrm{~h}$ at $37^{\circ} \mathrm{C}$. After washing with PBS three times, the cells were fixed with $4 \%$ paraformaldehyde solution and stained with $10 \mu \mathrm{g} / \mathrm{ml}$ Hoechst 33342 solution and $10 \mu \mathrm{g} / \mathrm{ml}$ rhodamine B for $1 \mathrm{~h}$ in the dark. Then, the treated cells were examined by confocal laser scanning microscopy (CLSM).

The cell uptake of MSNs-PTX and FA-PEG-MSNs-PTX was quantified by measuring the concentration of PTX in cells using HPLC. SMMC-7721 cells were treated with MSNsPTX and FA-PEG-MSNs-PTX $(100 \mu \mathrm{g} / \mathrm{ml})$ and incubated for $0.5,1$, and $2 \mathrm{~h}$. The cells were scraped, collected, and treated ultrasonically for $1 \mathrm{~h}$, and then $500 \mu \mathrm{l}$ of methylt-butyl ether was used for the extraction of PTX. After vortexing for $3 \mathrm{~min}$, the cell suspensions were centrifuged for $20 \mathrm{~min}$ at 10,000 rpm, and the organic layer was evaporated in a vacuum. Then, $30 \mu \mathrm{l}$ of methanol was used to redissolve the sample, and $20 \mu \mathrm{l}$ of the sample was subjected to analysis by HPLC.

2.7.4. Cell Apoptosis Assay. SMMC-7721 cells were seeded in a 6-well plate, and after a 24-h culture, pure PTX, MSNs-PTX, and FA-PEG-MSNs-PTX (equivalent to $5 \mathrm{ng} / \mathrm{ml}$ PTX) were suspended in 1640 culture medium and added to the 6-well plate. After being cultured for $48 \mathrm{~h}$, the cells were digested with trypsin, transferred to a centrifuge tube, and centrifuged for $5 \mathrm{~min}$ at $1000 \mathrm{rpm}$. The cells were collected and suspended in $500 \mu \mathrm{l}$ of binding buffer, and then $5 \mu \mathrm{l}$ of Annexin V-FITC and $5 \mu \mathrm{l}$ of PI were added to the cell suspension and the cell apoptosis was examined by flow cytometry. The Annexin VFITC exhibited a green fluorescence and the PI exhibited a red fluorescence.

2.7.5. Western Blot Analysis. SMMC-7721 cells were treated with pure PTX, MSNs-PTX, and FA-PEG-MSNs-PTX at a concentration of $5 \mathrm{ng} / \mathrm{ml}$ for $48 \mathrm{~h}$. The cells were then collected and incubated with lysis buffer and the concentration of the total cellular proteins obtained was estimated by BCA assay. For western blot analysis, proteins $(30 \mu \mathrm{g})$ from each sample were electrophoresed on polyacrylamide gel and then transferred to a nitrocellulose membrane. After blocking with $5 \%$ nonfat milk for $1 \mathrm{~h}$, the membranes were incubated with specific antibodies for anti-Bcl-2, Bax, and caspase- 3 at $4^{\circ} \mathrm{C}$ overnight, followed by incubation with secondary antibodies. The immunoblots were conjugated with horseradish peroxidase for $1 \mathrm{~h}$, and the protein bands were detected by enhanced chemiluminescence detection. The amount of proteins in each group was confirmed by $\beta$-actin.

\subsection{In Vivo Experiments}

2.8.1. Biodistribution in Nude Mice of MSNs-PTX and FAPEG-MSNs-PTX. Nude mice (female) with a body weight of about 20-25 g were used in this study, and they were obtained from Beijing Vital River Laboratory Animal Technology Co., Ltd. The mice were kept in a specific-pathogen-free (SPF) environment, and all experiments were carried out in compliance with the Animal Management Rules of the Jinzhou Medical University (2016).

The nude mice received subcutaneous inoculations of 5 $\times 10^{6}$ SMMC-7721 cells in the unilateral armpit. After cell inoculation, the longest diameter and the shortest diameter of the tumor were measured every 3 days and the tumor volume was calculated by the formula:

$$
\begin{aligned}
& \text { volume of tumor } \\
& =\frac{(\text { longest diameter }) \times(\text { shortest diameter })^{2}}{2} .
\end{aligned}
$$

The tumor volumes reached approximately $300 \mathrm{~mm}^{3}$ in about 25 days, and 42 mice were randomly divided into 2 groups. A saline suspension containing MSNs-PTX or FAPEG-MSNs-PTX (equivalent to 20 of mg PTX per kilogram of body weight) was administered by intraperitoneal injection, then, at $0.083,0.5,1,2,6,12$, and $24 \mathrm{~h}$, blood $(1 \mathrm{ml})$ and tissues from 3 mice were collected. The blood collected at the predetermined intervals was immediately centrifuged to obtain plasma. The heart, liver, spleen, lung, kidney, and tumor tissues were rinsed in saline, weighed, and then homogenized with DMSO. Samples $(200 \mu \mathrm{l})$ of the tissue homogenates or plasma $(100 \mu \mathrm{l})$ were transferred to $1.5-\mathrm{ml}$ microcentrifuge tubes and $20 \mu \mathrm{l}$ of butyl parahydroxybenzoate was added to each tube as an internal standard. Each mixture was vortexed for $3 \mathrm{~min}$, and $1 \mathrm{ml}$ of methyl-tbutyl ether was used to extract the PTX. After vortexing for $5 \mathrm{~min}$, the samples were centrifuged for $10 \mathrm{~min}$ at $10,000 \mathrm{rpm}$, 
<smiles>NC(=O)CSCCC(=O)NC(CCC(=O)O)C(=O)O</smiles>

Folic acid<smiles>Nc1nc(=O)c2nc(CNc3ccc(C(=O)NC(CCC(=O)ON4C(=O)CCC4=O)C(=O)O)cc3)cnc2[nH]1</smiles>

Activated folic acid<smiles>NOC(CCOCCC(=O)O)CC(=O)O</smiles>

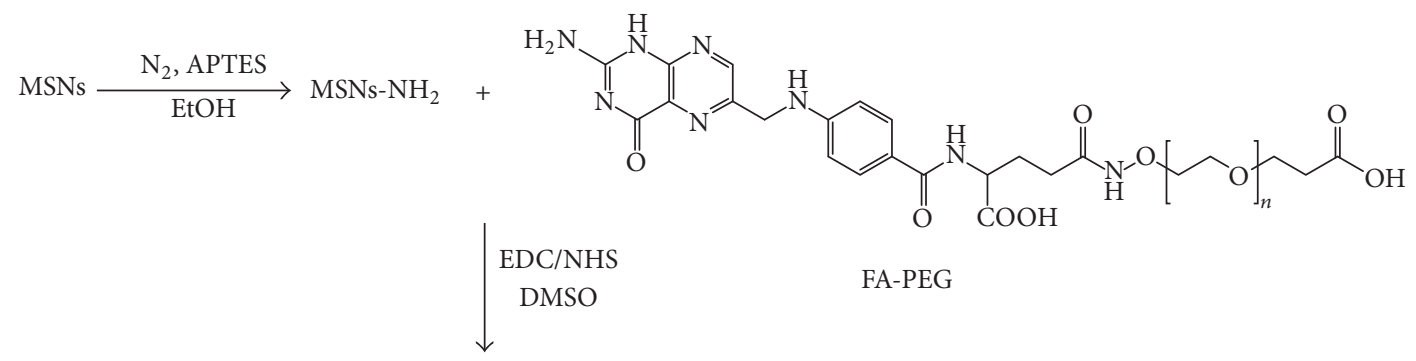<smiles>CC(CCOCCC(=O)NNS(C)(=O)=O)ONC(=O)CCC(NC(=O)c1ccc(NCc2cnc3[nH]c(N)nc(=O)c3n2)cc1)C(=O)O</smiles>

FA-PEG-MSNs

Figure 1: Synthesis scheme for FA-PEG-MSNs.

and the organic layer was transferred to another tube and volatilized in a vacuum. Then, $30 \mu \mathrm{l}$ of methanol was added to each tube to dissolve the samples and $20 \mu \mathrm{l}$ of each sample was subjected to HPLC. The mobile phase was a solution of acetonitrile and water $(50: 50, \mathrm{v} / \mathrm{v})$, the flow rate was set at $1.0 \mathrm{ml} / \mathrm{min}$, and the wavelength was $227 \mathrm{~nm}$.

2.8.2. Antitumor Activity of the MSNs-PTX or FA-PEG$M S N s-P T X$. Twenty-four nude mice were inoculated with SMMC-7721 tumor cells. When the volume of the primary tumor reached approximately $300 \mathrm{~mm}^{2}$, the nude mice were randomized into 4 groups in order to study the antitumor effect of MSNs-PTX or FA-PEG-MSNs-PTX. At a dose of $20 \mathrm{mg}$ of PTX per kilogram of body weight, 3 groups of mice were given pure PTX, MSNs-PTX, or FA-PEG-MSNs-PTX by intraperitoneal injection, and a fourth group of mice were given saline as a control group. Drug was administered 6 times at intervals of 3 days. The longest diameter and the shortest diameter of the tumor were measured using a Vernier caliper and the tumor volume was calculated as described above. The nude mice were then euthanized after the final administration, and the tumors were removed and weighed. The hearts, livers, spleens, lungs, kidneys, and tumors were collected, and the antitumor activity was evaluated by the tumor inhibition rate. The formula used was as follows:

$$
\text { Tumor inhibition rate }=\left(1-\frac{W_{t}}{W_{c}}\right) \times 100 \%,
$$

where $W_{t}$ is the mean weight of the tumor for each drug treatment group and $W_{c}$ is the mean weight of the tumor for the control group.

To study the effects of the MSNs-PTX and FA-PEGMSNs-PTX on the tumor tissues and potential toxic effects on organs, all samples were fixed in $4 \%$ paraformaldehyde solution and cut into slices after paraffin imbedding. All slices were stained with hematoxylin-eosin and observed under a digital microscope.

2.9. Data Processing and Statistical Analysis. The results of all experiments were reported as the mean \pm SD. Statistical significance was analyzed by ANOVA for multiple groups and $P<0.05$ was considered to be statistically significant.

\section{Results and Discussion}

3.1. Synthesis of FA-PEG and FA-PEG-MSNs. The synthesis of FA-PEG-MSNs is shown in Figure 1. FA-PEG was synthesized 


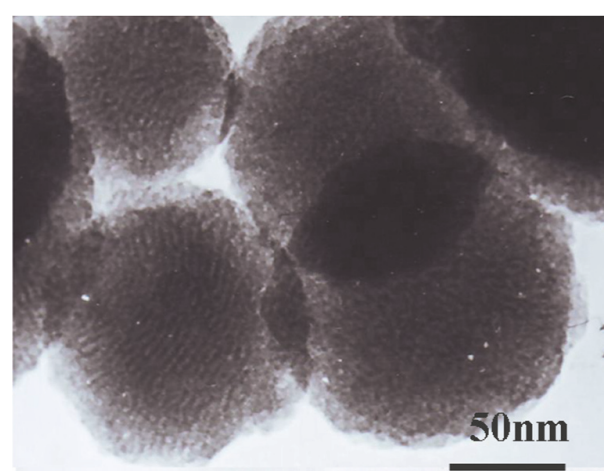

(a)

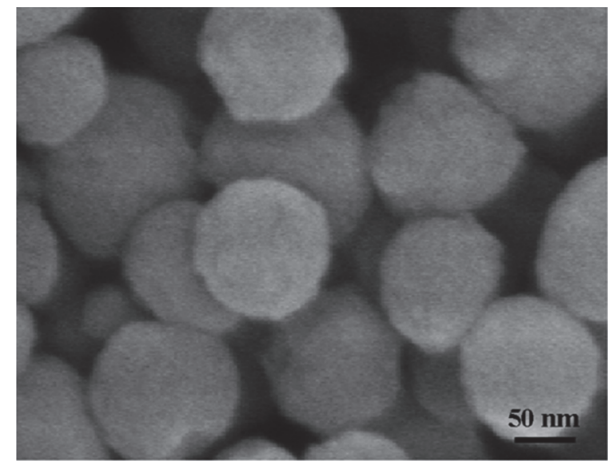

(c)

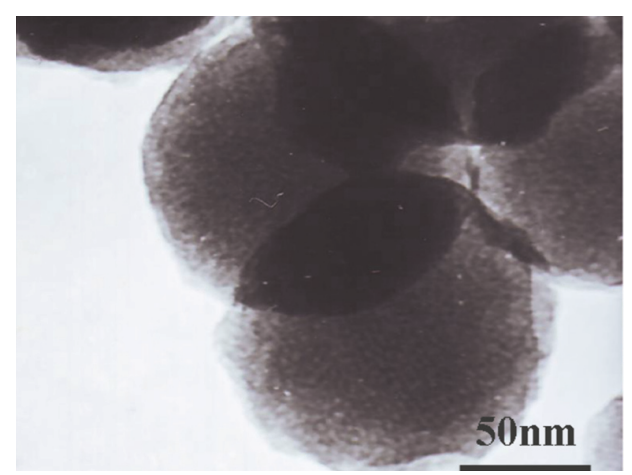

(b)

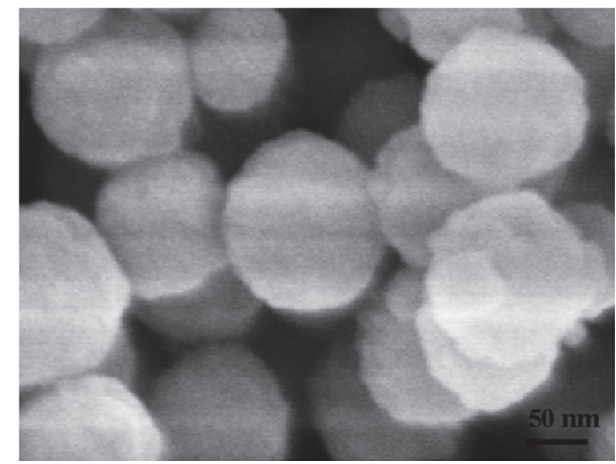

(d)

FIgure 2: The SEM images of (a) MSNs; (b) FA-PEG-MSNs. The TEM images of (c) MSNs; (d) FA-PEG-MSNs.

by reaction of the bifunctional PEG and the activated folic acid with an excess of DCC and NHS. As shown in the ${ }^{1} \mathrm{H}$ NMR spectra (Figure 3(a)), the characteristic peaks at 6.72, 7.61 p.p.m represented four protons of the p-phenyl ring in FA and the peaks at 3.51,3.39 p.p.m represented the ethyoxyl group of the PEG, which confirmed the conjugation of PEG and FA. Modification of MSNs with FA-PEG was confirmed by FTIR (Figure 3(b)). In the spectrum of FA-PEG-MSNs, the characteristic peaks at 1718 and $3425 \mathrm{~cm}^{-1}$ were assigned as the $\mathrm{C}=\mathrm{O}$ and $\mathrm{N}-\mathrm{H}$ stretching of amide bond, and the peak at 2927 was the functional group of PEG $\left(\mathrm{CH}_{2}\right)$, which showed that the FA-PEG-MSNs had been successfully prepared.

3.2. Characterization of MSNs and FA-PEG-MSNs. The morphology and structure of MSNs and FA-PEG-MSNs were observed by SEM and TEM, respectively. As shown in Figures 2(a) and 2(b), the TEM images indicated that MSNs and FA-PEG-MSNs were monodispersed spherical particles with average sizes of $100 \mathrm{~nm}$, which agreed with the SEM (Figures $2(c)$ and $2(d))$ results. This suggested that, after modification with FA-PEG, the morphology and structure of MSNs were unchanged.

3.3. Physicochemical Characterization. The state of PTX in MSNs-PTX and FA-PEG-MSNs-PTX was assessed by DSC and PXRD analysis [32]. As shown in Figure 4(a), pure PTX exhibited a sharp endothermic peak at $223.0^{\circ} \mathrm{C}$, which was the PTX intrinsic melting point. PPM and PPFA also exhibited an endothermic peak at $223.0^{\circ} \mathrm{C}$. Neither the MSNs-PTX nor the FA-PEG-MSNs-PTX thermograms exhibited a phase transition of PTX, which showed that the PTX was in an amorphous state in MSNs and FA-PEG-MSNs.

The state of PTX was further confirmed by XRD analysis. As shown in Figure 4(b), pure PTX exhibited intense and typical diffraction peaks at $2 \theta=12.3^{\circ}$, and PPM also exhibited a diffraction peak at $2 \theta=12.3^{\circ}$. The characteristic peaks of PPFA were still visible as a result of the PTX being in a crystalline state. However MSNs-PTX and FAPEG-MSNs-PTX did not show any characteristic diffraction peaks, indicating that the PTX was in an amorphous state in MSNs and FA-PEG-MSNs, which was in agreement with the DSC results. PTX was adsorbed into the mesopore structure of MSNs and FA-PEG-MSNs, and the limited nanospace inhibited the crystalline state of PTX.

3.4. Drug Encapsulation and In Vitro Dissolution Testing. The HPLC analysis showed that the drug loading of MSNs and FA-PEG-MSNs was $32.43 \pm 2.01 \%$ and $24.26 \pm 1.52 \%$, respectively. This suggested that the specific surface area of the carrier was slightly reduced after the modification and the drug loading was correspondingly reduced.

The dissolution profiles of pure PTX, MSNs-PTX, and FA-PEG-MSNs-PTX are shown in Figure 3(c). Both FA-PEGMSNs-PTX and MSNs-PTX showed significantly higher dissolution rates in comparison with pure PTX. The amount of dissolved PTX in the dissolution medium at $1 \mathrm{~h}$ reached 


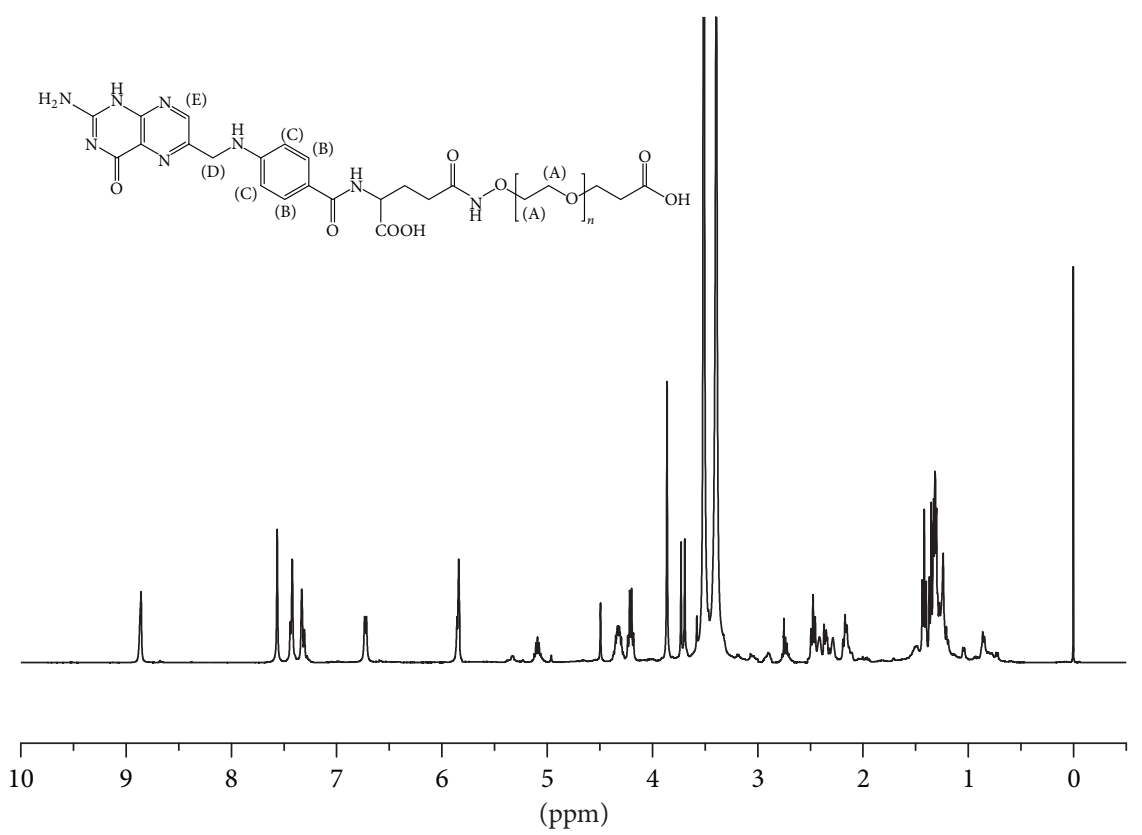

(a)

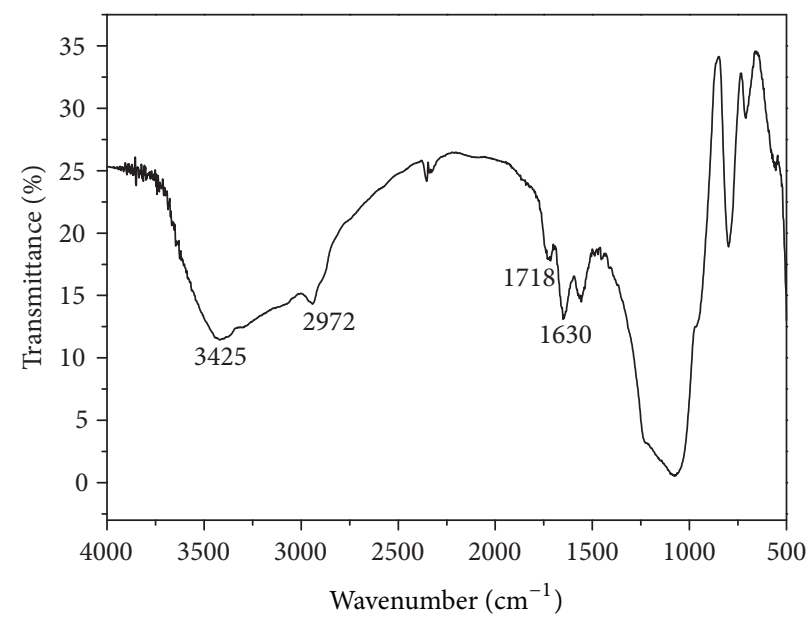

(b)

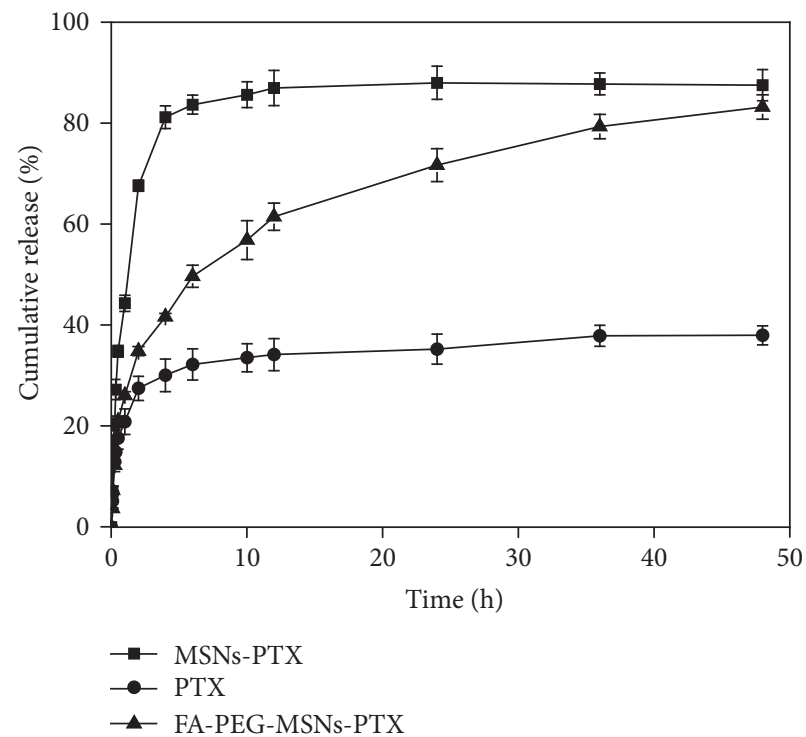

(c)

Figure 3: (a) The ${ }^{1}$ H NMR spectrum of FA-PEG. (b) The FTIR spectrum of FA-PEG-MSNs. (c) In vitro drug release curves of pure PTX, MSNs-PTX, and FA-PEG-MSNs-PTX $(n=3)$.

$20.88 \pm 2.52 \%$ for pure PTX, while the corresponding amounts were $26.09 \pm 0.75 \%$ and $44.33 \pm 1.61 \%$ for FA-PEG-MSNsPTX and MSNs-PTX, respectively. The release of FA-PEGMSNs-PTX and MSNs-PTX was more than $80 \%$ within $48 \mathrm{~h}$, while the release of pure PTX was less than $30 \%$ after $48 \mathrm{~h}$. The reason for the faster release of MSNs-PTX was that the mesoporous structure of MSNs limited the particle size of PTX and maintained PTX in a noncrystalline state. The FAPEG-MSNs-PTX exhibited a sustained release, which was attributed to an increase in the diffusion resistance of the FA-PEG-MSNs due to modification of the FA-PEG-chain on the surface of MSNs. The sustained-release effect could maintain the therapeutic concentration of the drug, prolong its action, increase its anticancer effect, reduce the frequency of administration, and improve patient compliance.

3.5. In Vitro Cytotoxicity. The cytotoxic effects of FA-PEGMSNs and MSNs obtained by MTT assay are shown in Figure 5(a). After a 48-h incubation with MSNs and FA-PEGMSNs, cell viability remained above $90 \%$, which showed that MSNs and FA-PEG-MSNs have excellent cell biocompatibility.

The cell viability of MSNs-PTX and FA-PEG-MSNs-PTX is shown in Figure 5(b). FA-PEG-MSNs-PTX and MSNsPTX exhibited significantly reduced cell viability compared 


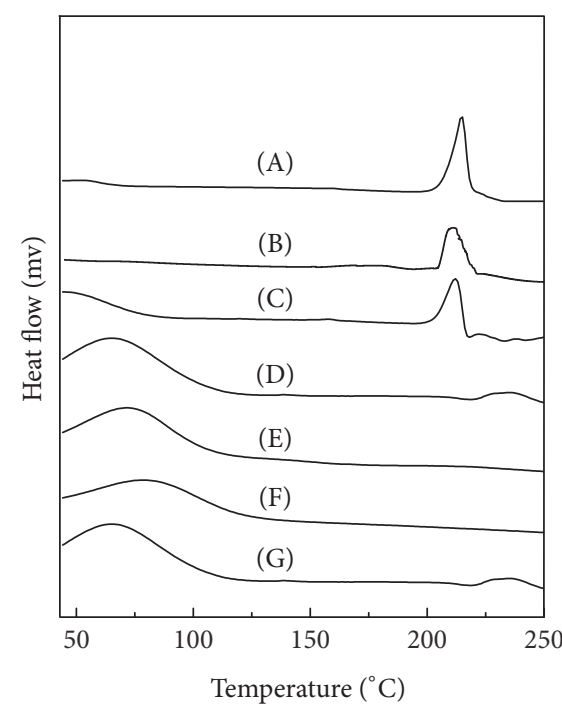

(a)

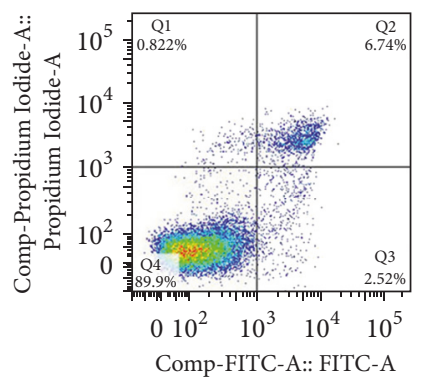

(A)

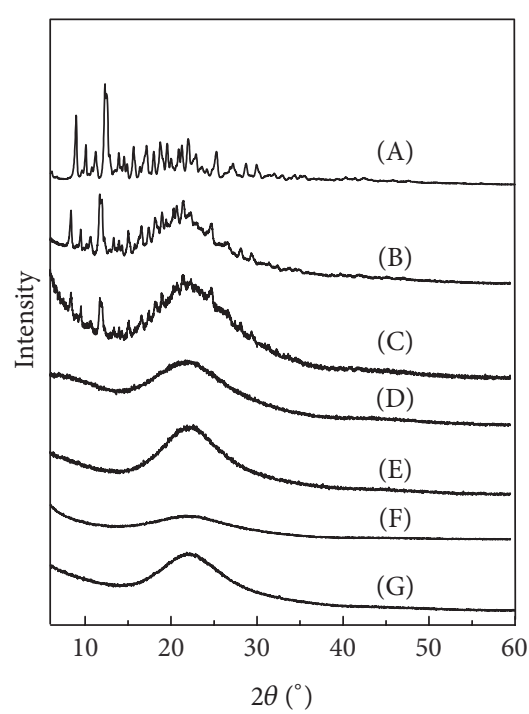

(b)
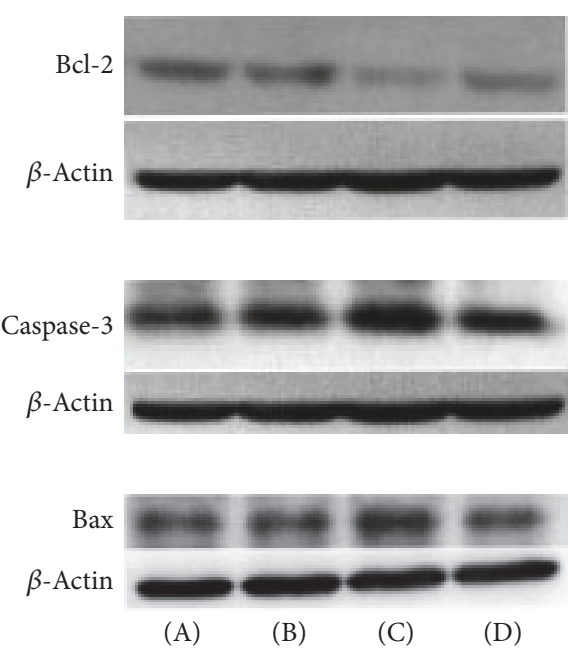

(c)

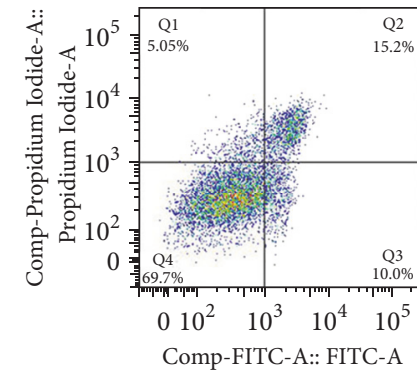

(B)

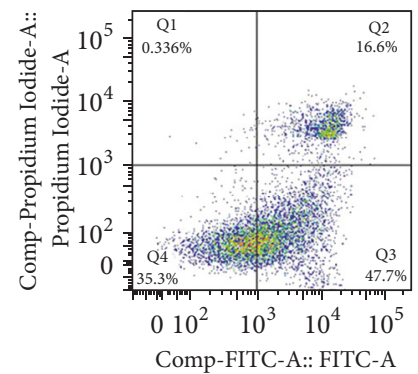

(C)

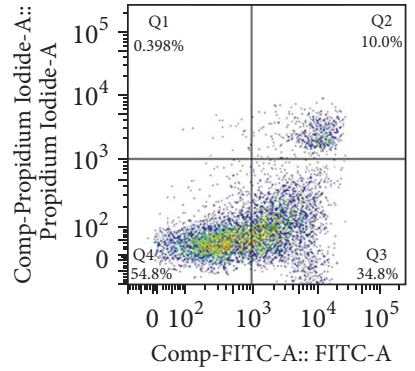

(D)

(d)

Figure 4: (a) The DSC patterns. (b) PXRD patterns of (A) pure PTX, (B) PPM, (C) PPFA, (D) MSNs-PTX, (E) FA-PEG-MSNs-PTX, (F) MSNs, and (G) FA-PEG-MSNs. (c) Immunoblots showing the effect of FA-PEG-MSNs-PTX on the expression of Bcl-2, caspase-3, Bax in cells treated with (A) the control group, (B) pure PTX, (C) FA-PEG-MSNs-PTX, and (D) MSNs-PTX. (d) The flow cytometry plots of SMMC-7721 cells treated with (A) the control group, (B) pure PTX, (C) FA-PEG-MSNs-PTX, and (D) MSNs-PTX.

with pure PTX and the cell viability of FA-PEG-MSNsPTX and MSNs-PTX at a concentration of $100 \mathrm{ng} / \mathrm{ml}$ was $40.22 \pm 5.29 \%$ and $51.08 \pm 5.67 \%$, respectively, while the cell viability of pure PTX was $80.3 \pm 4.91 \%$. The cytotoxicity of MSNs-PTX and FA-PEG-MSNs-PTX gradually increased with an increase in concentration and FA-PEGMSNs-PTX exhibited the greatest inhibitory effect. When the concentration reached $500 \mathrm{ng} / \mathrm{ml}$, the cell viability of FA-PEG-MSNs-PTX and MSNs-PTX was $32.86 \pm 4.99 \%$ and $35.49 \pm 4.51 \%$, respectively. By comparison, the cell viability of pure PTX was $68.95 \pm 4.99 \%$. The value of the half maximal inhibitory concentration (IC50) of MSNs-PTX and FA-PEG-MSNs-PTX was $109.769 \pm 13.16 \mathrm{ng} / \mathrm{ml}$ and $71.969 \pm 9.75 \mathrm{ng} / \mathrm{ml}$, respectively. For pure PTX, the IC50 value was $622.24 \pm 47.12 \mathrm{ng} / \mathrm{ml}$. Clearly, FA-PEG-MSNsPTX had a better antitumor effect than pure PTX or MSNsPTX. The in vitro cytotoxicity of FA-PEG-MSNs-PTX was significantly increased because the folate receptors on the cell membranes could specifically combine with the folate on FA-PEG-MSNs-PTX, leading to the accumulation of PTX in hepatocellular carcinoma cells. The FA-PEG-MSNs-PTX exhibited a favorable targeting action compared with MSNsPTX.

3.6. Cellular Uptake of MSNs and FA-PEG-MSNs. The mechanism of cellular uptake of MSNs-PTX and FA-PEG-MSNsPTX is shown in Scheme 1. The cellular uptake of FITC-MSNs and FITC-FA-PEG-MSNs observed by confocal microscopy is shown in Figure 7. It was clear that the FITC-MSNs and FITC-FA-PEG-MSNs were endocytosed in the cytoplasm of SMMC-7721 cells based on the intense yellow fluorescence that was a superimposition of the green fluorescence of FITCMSNs and FITC-FA-PEG-MSNs and the red fluorescence of the cytoskeleton. At $0.5 \mathrm{~h}$, the yellow fluorescence was relatively weak and the cellular uptake of FITC-MSNs and FITC-FA-PEG-MSNs was relatively low. Over time, the density of the yellow fluorescence increased, indicating that the uptake of FITC-MSNs and FITC-FA-PEG-MSNs was time-dependent. Furthermore, compared with the FITCMSNs at the same time, it was clear that the FITC-FA-PEGMSNs exhibited a stronger yellow fluorescence, suggesting that modification with FA could increase the cell uptake of 
TABle 1: Pharmacokinetic parameters of MSNs-PTX and FA-PEG-MSNs-PTX $(n=3)$.

\begin{tabular}{lccccc}
\hline & $t_{1 / 2}(\mathrm{~h})$ & $T_{\max }(\mathrm{h})$ & $C_{\max }(\mu \mathrm{g} / \mathrm{ml})$ & AUC $(\mu \mathrm{g} / \mathrm{ml} * \mathrm{~h})$ & $\mathrm{MRT}(\mathrm{h})$ \\
\hline MSNs-PTX & $6.489 \pm 0.449$ & $1.04 \pm 0.12$ & $4.736 \pm 0.899$ & $24.102 \pm 2.919$ & $9.552 \pm 0.442$ \\
FA-PEG-MSNs-PTX & $12.464 \pm 0.791$ & $0.89 \pm 0.10$ & $4.983 \pm 1.175$ & $34.367 \pm 3.184$ & $15.368 \pm 0.954$ \\
\hline
\end{tabular}

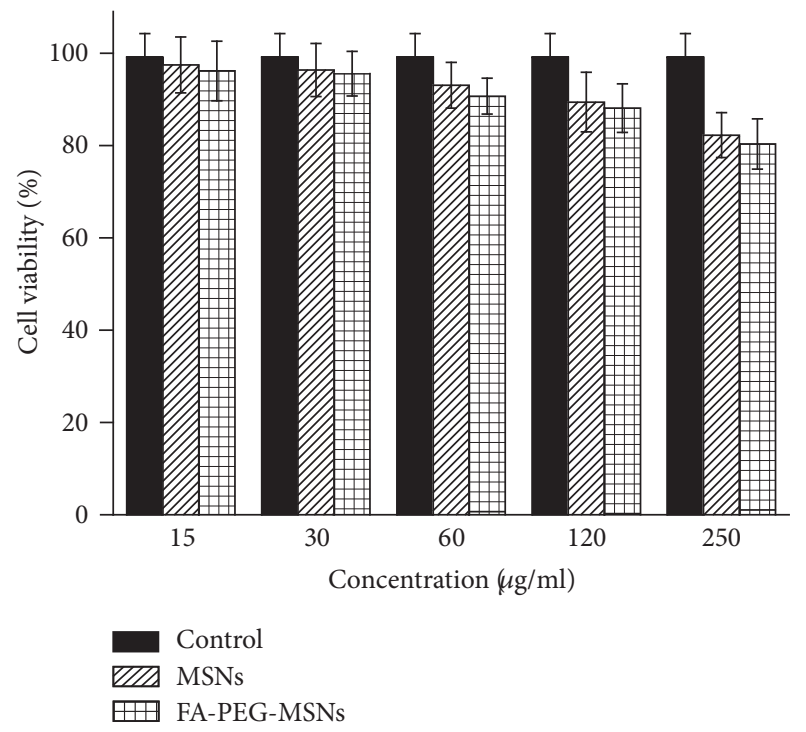

(a)

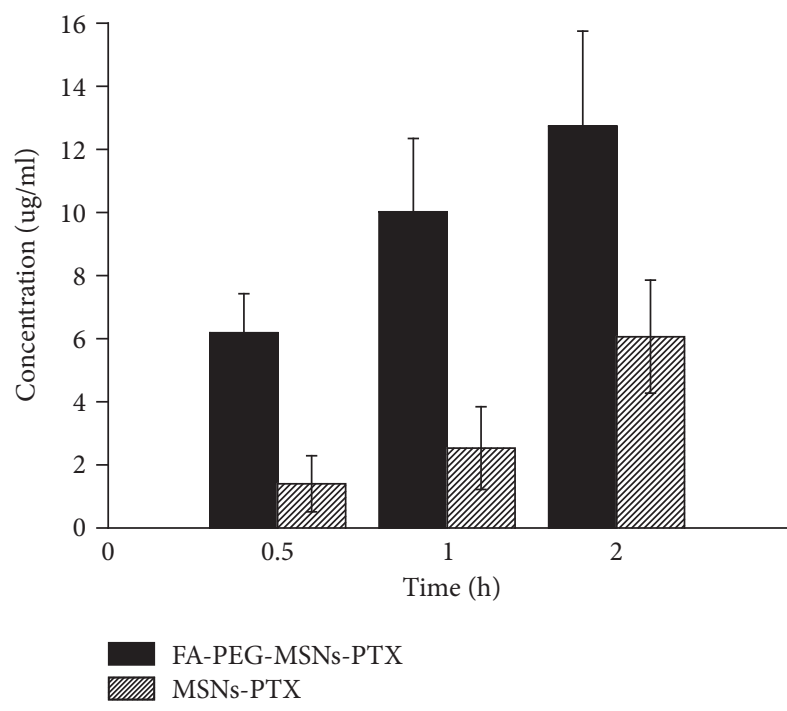

(c)

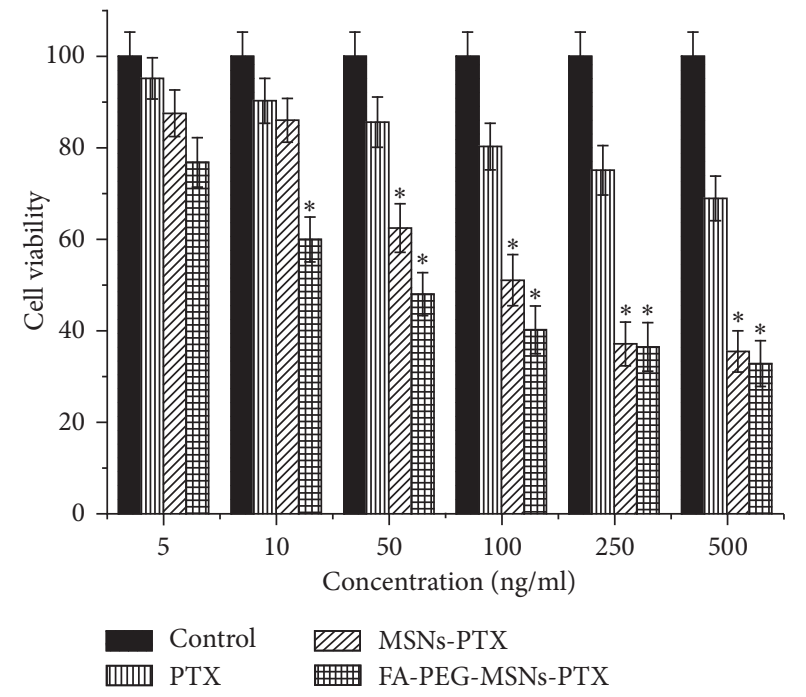

(b)

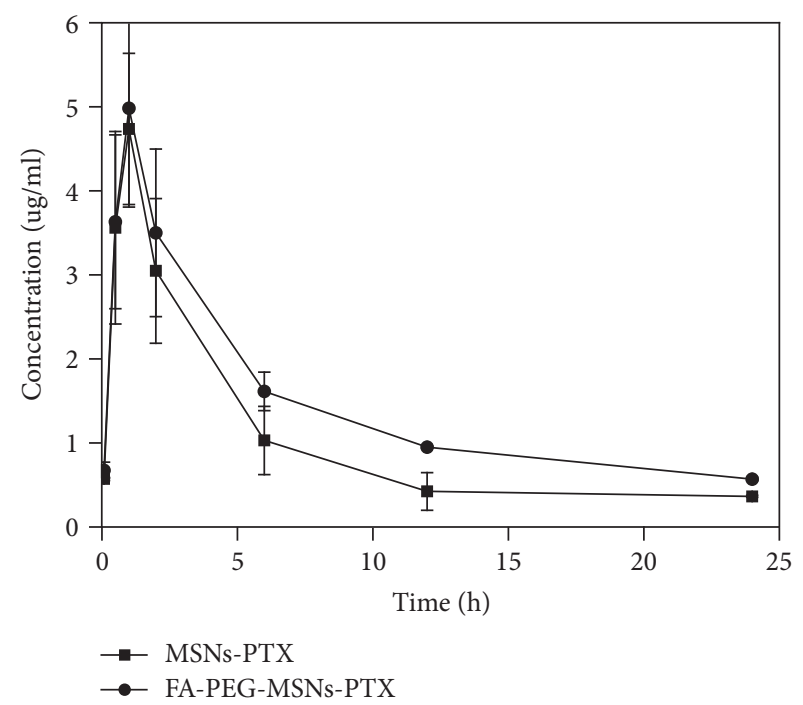

(d)

FIGURE 5: The cell viability of SMMC-7721 cells incubated with (a) blank MSNs and FA-PEG-MSNs; (b) MSNs-PTX and FA-PEG-MSNsPTX for $48 \mathrm{~h}$, respectively $(n=6)$. (c) The PTX concentration in cells treated with FA-PEG-MSNs-PTX and MSNs-PTX for $0.5,1$, and $2 \mathrm{~h}$, respectively $(n=3)$. (d) The plasma concentration-time curves of FA-PEG-MSNs-PTX and MSNs-PTX $(n=3)$. $*$ stands for $P<0.05$.

FITC-FA-PEG-MSNs. Also, the quantitative determination of PTX taken up by cells further validated the CLSM results. As shown in Figure 5(c), the PTX concentration in cells treated with FA-PEG-MSNs-PTX was $12.728 \pm 3.019 \mu \mathrm{g} / \mathrm{ml}$ at $3 \mathrm{~h}$. This was significantly higher than that of the group treated with MSNs-PTX $(6.062 \pm 1.789 \mu \mathrm{g} / \mathrm{ml})$ and showed time dependence. The efficient cellular uptake of FA-PEGMSNs could increase the absorption of PTX and improve the inhibition of cancer cell growth.

3.7. Cell Apoptosis Assay. An Annexin V-FITC binding assay was carried out using Annexin V-FITC and propidium iodide 


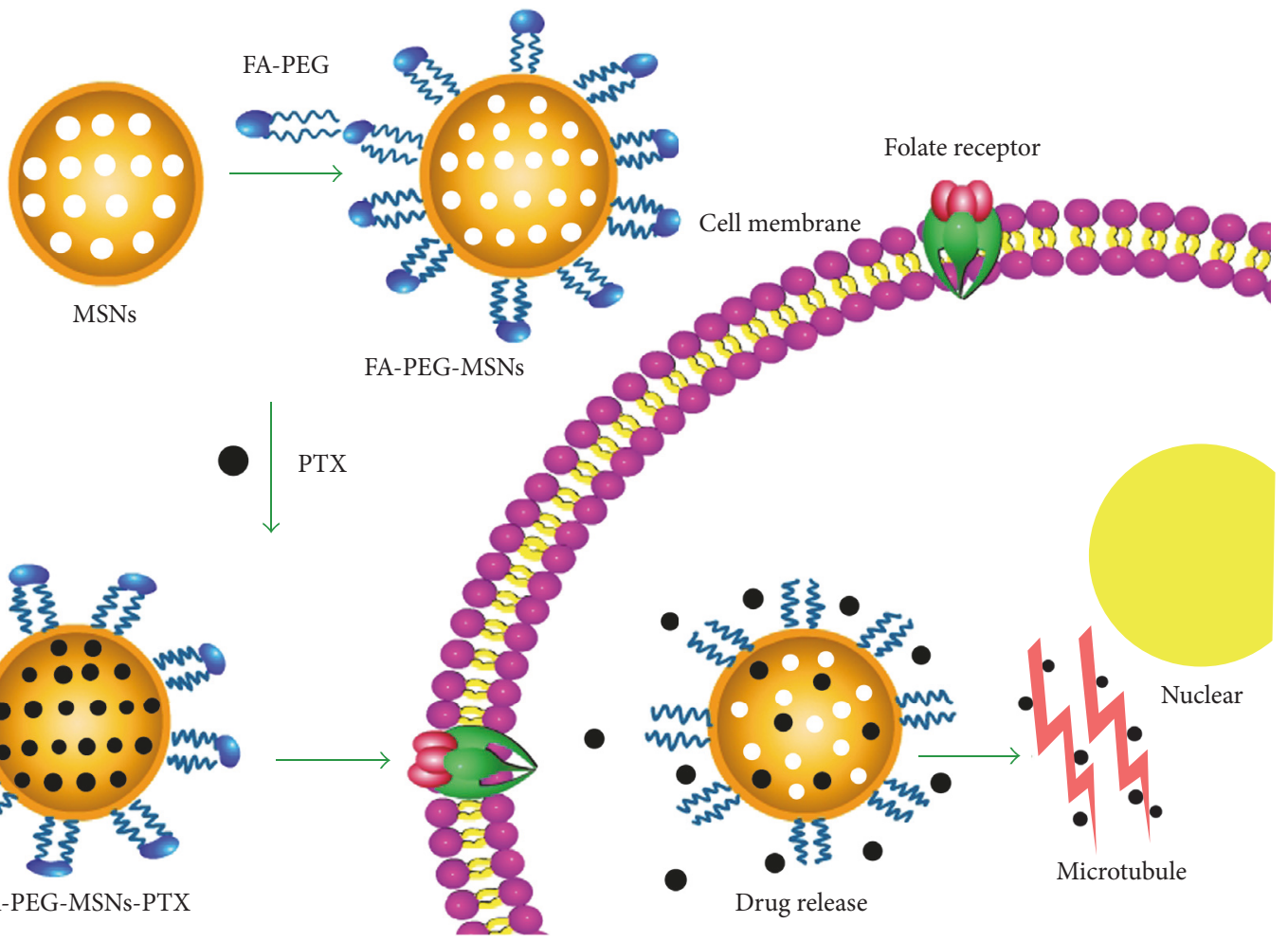

Scheme 1: Illustration of the synthesis and chemical modification of FA-PEG-MSNs, PTX loading, and drug release.

(PI) to confirm the cell apoptosis. As shown in Figure 4(d), FA-PEG-MSNs-PTX and MSNs-PTX showed significantly higher apoptosis compared with pure PTX. The percentage of cells in early apoptosis treated with FA-PEG-MSNs-PTX and MSNs-PTX was $47.6 \pm 1.3 \%$ and $35.2 \pm 2.1 \%$, respectively. By contrast, the corresponding figure for pure PTX was $10.0 \%$. Due to effective targeting, the higher uptake of FA-PEGMSNs-PTX for SMMC-7721 cells through the endocytosis pathway led to an increase in the concentration of PTX in cells, which resulted in greater apoptotic effects. This indicated that using FA-PEG-MSNs as a carrier could improve the antitumor effect of PTX.

3.8. Expression of Apoptotic Proteins. The cell apoptosis signaling pathway is mediated by caspases and the caspase3 proteins are crucial mediators of apoptosis. Bcl-2 and Bax, typical proteins of the Bcl-2 family, play key roles in caspase-dependent apoptosis. Bcl-2 is an antiapoptotic protein and Bax promotes apoptosis protein [33, 34]. As seen in Figure 4(c), SMMC-7721 cells treated with FA-PEG-MSNsPTX significantly upregulated the expression of caspase-3 and Bax in comparison with pure PTX and MSNs-PTX. The Bcl-2 expression of the cells treated with FA-PEG-MSNsPTX was significantly downregulated in comparison with MSNs-PTX. The western blot assay indicated that FA-PEGMSNs-PTX could significantly promote apoptosis, and this was attributed to the excellent targeting of FA-PEG-MSNs.

3.9. In Vivo Biodistribution of FA-PEG-MSNs-PTX and MSNs$P T X$. The plasma drug concentration-time curves of FAPEG-MSNs-PTX and MSNs-PTX are shown in Figure 5(d), and the pharmacokinetic parameters are presented in Table 1. The plasma half-life $\left(t_{1 / 2}\right)$ was $12.464 \pm 0.791 \mathrm{~h}$ and $6.489 \pm$ $0.449 \mathrm{~h}$ for the FA-PEG-MSNs-PTX group and MSNs-PTX group, respectively. The longer $t_{1 / 2}$ of the FA-PEG-MSNsPTX group prolonged the in vivo drug action time, which helped reduce the dosage and time of administration. The AUC of FA-PEG-MSNs-PTX was $34.367 \pm 3.184 \mu \mathrm{g} / \mathrm{ml} * \mathrm{~h}$, which was approximately 1.5 times greater than that of MSNsPTX. These results indicated that FA-PEG-MSNs-PTX had higher bioavailability.

The biodistribution patterns of MSNs-PTX and FA-PEGMSNs-PTX in nude mice bearing SMMC-7721 tumors after a single intraperitoneal injection are shown in Figures 6(c) and $6(\mathrm{~d})$. The PTX concentration in the tumor tissue of the FA-PEG-MSNs-PTX group was significantly increased over $12 \mathrm{~h}$ while the PTX concentration in tumor tissue for the MSNs-PTX group declined after $2 \mathrm{~h}$ and the MSNs-PTX was rapidly eliminated by the reticuloendothelial system (RES) [35]. The maximum concentration in tumor tissue of the FA-PEG-MSNs-PTX group was $277.78 \pm 49.21 \mu \mathrm{g} / \mathrm{g}$, almost 10.25 times as high as that in the MSNs-PTX group (27.33 \pm $14.11 \mu \mathrm{g} / \mathrm{g}$ ). These results demonstrated that FA-PEG-MSNsPTX significantly increased the tumor accumulation of PTX, confirming that FA-PEG-MSNs exhibited excellent tumor targeting and could increase the tumor delivery of PTX.

The liver is the most important organ in the RES [36]. The concentration of PTX in the liver was highest compared with the other organs. The biodistribution of PTX in the spleen and lung was similar to that in the liver, while in the heart and kidney, the concentration of PTX was lower than in other 


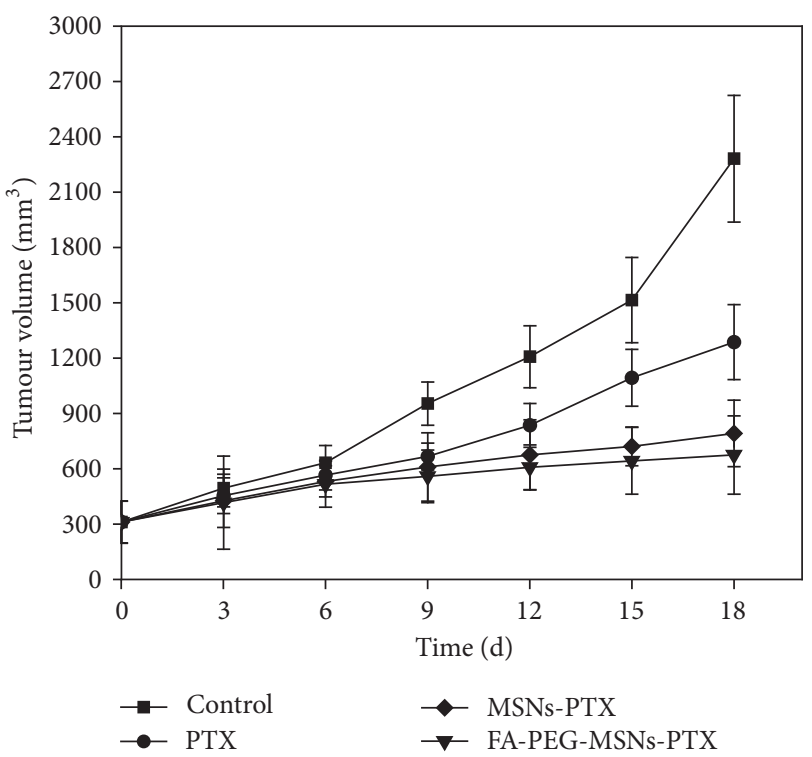

(a)

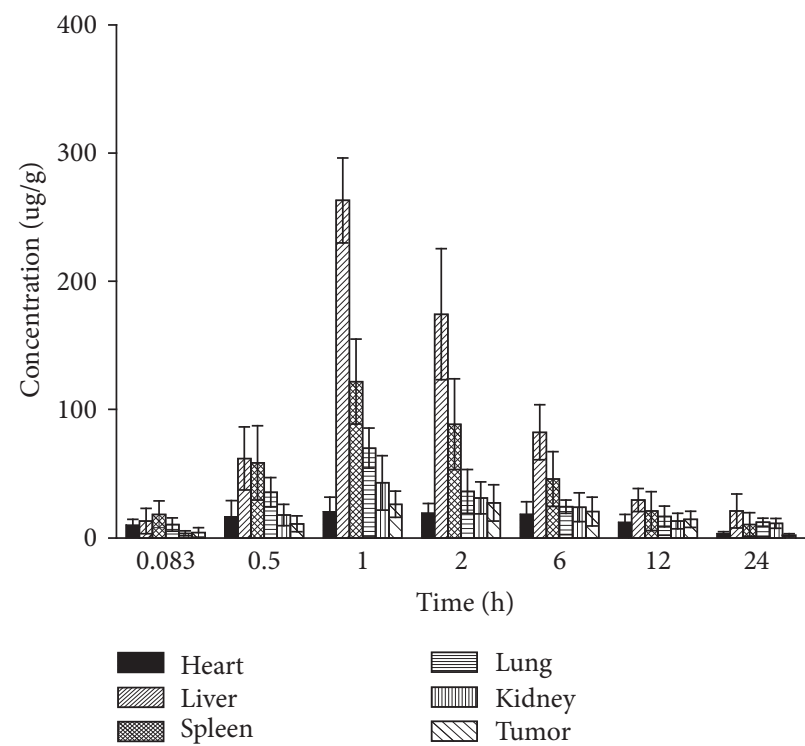

(c)

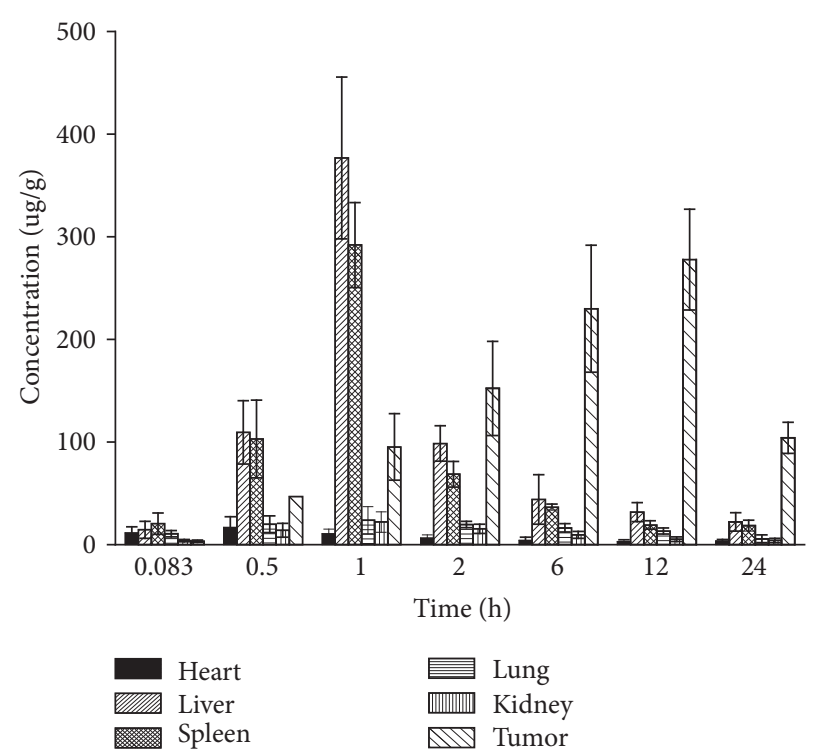

(d)

FIGURE 6: (a) Antitumor effects (in terms of tumor growth) of the control group, pure PTX, FA-PEG-MSNs-PTX, and MSNs-PTX on tumorbearing mice after intraperitoneal injection $(n=6)$. (b) Images of tumors from each treatment group following excision on day 21 . Drug biodistribution of (c) MSNs-PTX and (d) FA-PEG-MSNs-PTX in the major organs and tumors after a single intraperitoneal injection $(n=3)$.

organs, and the PTX concentration decreased from $1 \mathrm{~h}$ to $24 \mathrm{~h}$. The tumor targeting of FA-PEG-MSNs-PTX caused a lower biodistribution of PTX in organs (except the tumor) compared with MSNs-PTX, which reduced the damage to normal cells and reduced patient discomfort.

3.10. In Vivo Antitumor Effect. The antitumor effects of MSNs-PTX and FA-PEG-MSNs-PTX are shown in Figure 6(a). The tumor volume of MSNs-PTX and FA-PEGMSNs-PTX was smaller than that of the control group, and FA-PEG-MSNs-PTX exhibited the most significant tumor inhibition effect. After the last administration, the average tumor volume of the saline group was $2281.4 \pm 343.0 \mathrm{~mm}^{3}$.
In comparison, the value for the pure PTX group was $1586.9 \pm 203.9 \mathrm{~mm}^{3}$. The tumor inhibition rate of the pure PTX group was $30.44 \pm 1.32 \%$. For the MSNs-PTX group and the FA-PEG-MSNs-PTX group, the average tumor volume was $991.5 \pm 180.7 \mathrm{~mm}^{3}$ and $674.7 \pm 212.8 \mathrm{~mm}^{3}$, respectively. Clearly, treatment with FA-PEG-MSNs-PTX was significantly better at inhibiting tumor growth. The tumor inhibition rate of FA-PEG-MSNs-PTX was $70.43 \pm 4.22 \%$ compared with $56.54 \pm 1.19 \%$ for MSNs-PTX. The tumor inhibition rates between any two groups were significantly different $(P<0.05)$. These results further confirmed that FAPEG-MSNs exhibited good targeting ability. 


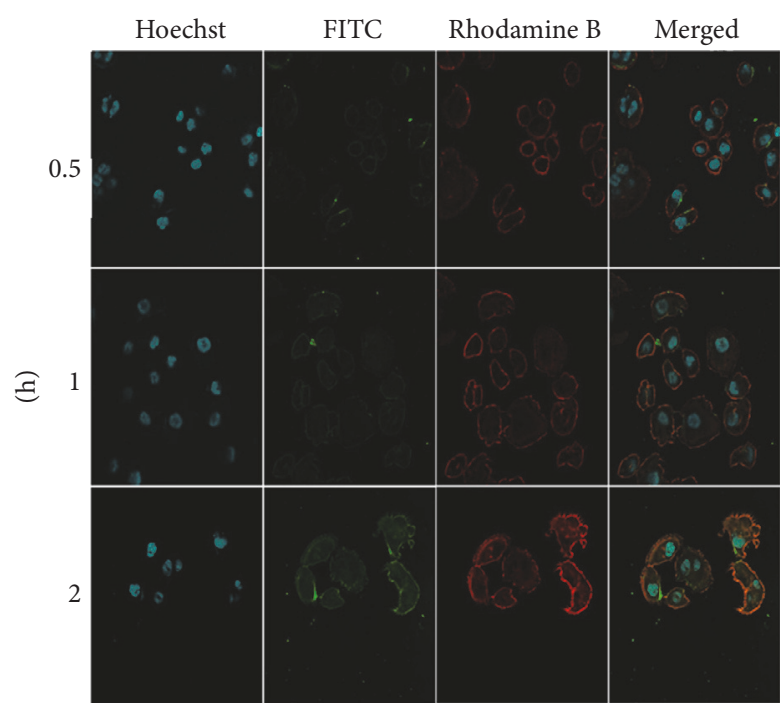

(a)

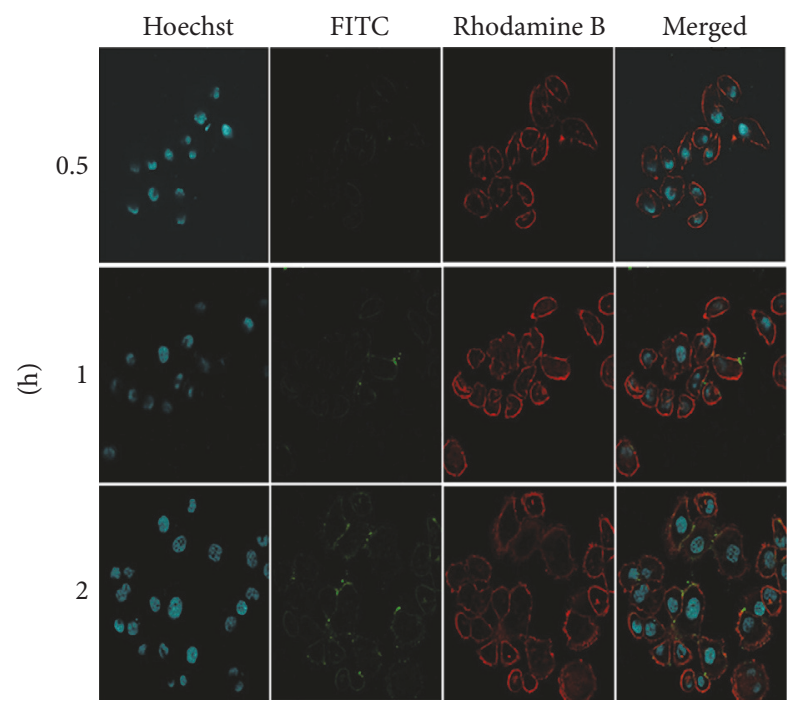

(b)

FIGURE 7: Confocal laser scanning microscopy (CLSM) images of SMCC-7721 cells incubated with (a) FA-PEG-MSNs and (b) MSNs for 0.5, 1 , and $2 \mathrm{~h}$, respectively.

(A)

(B)

(C)

(D)

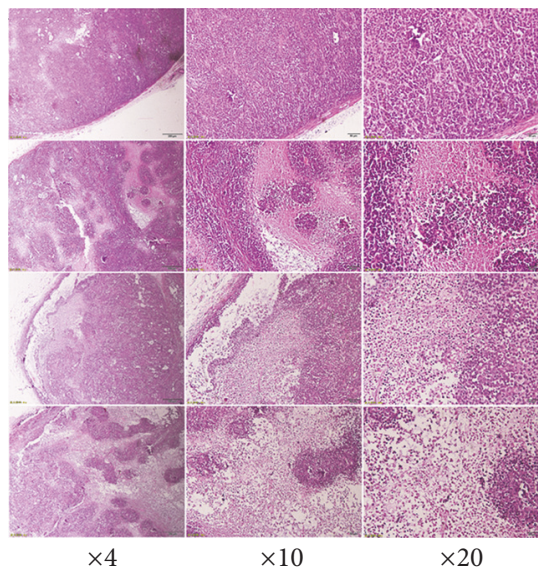

(a)

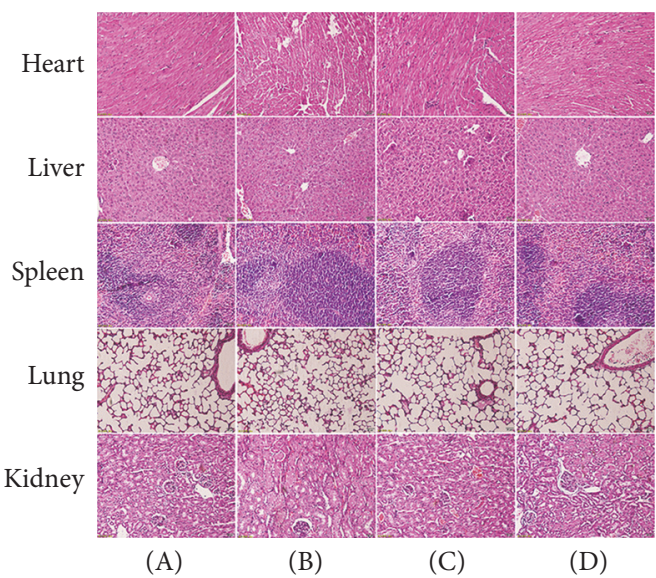

(b)

FIGURE 8: (a) Histomicrographs of hematoxylin/eosin-stained sections of tumor tissue of the (A) control group, (B) pure PTX, (C) MSNsPTX, and (D) FA-PEG-MSNs-PTX. (b) Histomicrographs of hematoxylin/eosin-stained sections of major organs and tissues of the (A) control group, (B) pure PTX, (C) MSNs-PTX, and (D) FA-PEG-MSNs-PTX.

3.11. Histological Analysis. The tumor tissue histological sections of the FA-PEG-MSNs-PTX group showed significant changes compared with the other groups. As shown in Figure 8(a), there were fewer blood vessels in tumor tissue and more necrotic cells and apoptotic cells compared with the saline group, pure PTX group, and MSNs-PTX group. In other organs, including the heart, liver, spleen, lungs, and kidneys (Figure 8(b)), there were no obvious differences between the FA-PEG-MSNs-PTX group, the MSNs-PTX group, and the pure PTX group, demonstrating that there was no tissue damage, inflammation, or lesions. So, FA-PEGMSNs-PTX is a very biocompatible drug delivery system.

\section{Conclusion}

In this study, a functional drug delivery system (FA-PEGMSNs) was successfully prepared, characterized, and shown to exhibit a sustained release. The FA multifunctionalized MSNs increased the cellular uptake and had excellent targeting ability and higher cytotoxic effects on SMMC-7721 cells. In vivo experiments revealed that FA-PEG-MSNsPTX exhibited higher drug accumulation in tumors and an excellent tumor growth inhibitory effect. In brief, these results proved that FA-PEG-MSNs-PTX was a new drug nanocarrier for the efficient delivery of PTX to hepatocarcinoma cells, 
especially for applications involving liver cancer chemotherapy.

$\begin{array}{ll}\text { Abbreviations } \\ \text { FA-PEG-MSNs: } & \text { Folate-PEG-mesoporous silica } \\ & \text { nanoparticles } \\ \text { PTX: } & \text { Paclitaxel } \\ \text { MSNs-PTX: } & \begin{array}{l}\text { Mesoporous silica nanoparticles loaded } \\ \text { with paclitaxel }\end{array} \\ \text { APTES: } & \text { Aminopropyltriethoxysilane } \\ \text { TEOS: } & \text { Tetraethylorthosilicate } \\ \text { MTT: } & \text { 3-(4,5-Dimethylthiazol-2-yl)-2,5- } \\ & \text { diphenyltetrazolium } \\ \text { CTAB: } & \text { Hypromellose, hexadecyl trimethyl } \\ & \text { ammonium bromide } \\ \text { DSC: } & \text { Differential scanning calorimetry } \\ \text { XRD: } & \text { X-ray diffraction analysis } \\ \text { AUC: } & \text { The area under concentration-time curve } \\ \text { FITC: } & \text { Fluorescein isothiocyanate. }\end{array}$

\section{Conflicts of Interest}

The authors declare that there are no conflicts of interest regarding the article.

\section{Authors' Contributions}

Xiaoyan Xu and Andi Bai prepared carrier material and studied in vitro properties of the drug delivery system and the animal research. Xiaoyan $\mathrm{Xu}$, Xuan Liu, Huiling Lv, and Ying Liu were mainly responsible for cell biology research. Chao Wu designed the experimental plan.

\section{Acknowledgments}

The authors are very grateful to Dr. David Jack for providing the professional language services. This study was supported by the National Natural Science Foundation of China (no. 81302707), Dr. Start-Up Foundation of Liaoning Province (no. 20141195), Program for Liaoning Excellent Talents in University (no. LJQ2015065), and Quanmin Oral Graduate Sci-Tech Innovation Foundation, the President Fund of Jinzhou Medical University (no. AH2015014).

\section{References}

[1] Y.-Q. Huang, X. Lu, H. Min et al., "Green tea and liver cancer risk: A meta-analysis of prospective cohort studies in Asian populations," Nutrition Journal, vol. 32, no. 1, pp. 3-8, 2016.

[2] Cancer, 2017. http://www.who.int/mediacentre/factsheets/fs297/ en/.

[3] J. G. Chen and S. W. Zhang, "Liver cancer epidemic in China: past, present and future," Seminars in Cancer Biology, vol. 21, no. 1, pp. 59-69, 2010.

[4] Y. Lu, Y. Li, and W. Wu, "Injected nanocrystals for targeted drug delivery," Acta Pharmaceutica Sinica B (APSB), vol. 6, no. 2, pp. 106-113, 2016.
[5] L. L. Wang, Z. H. Liu, D. H. Liu, C. Liu, Z. Juan, and N. Zhang, "Docetaxel-loaded-lipid-based-nanosuspensions (DTX-LNS): Preparation, pharmacokinetics, tissue distribution and antitumor activity," International Journal of Pharmaceutics, vol. 413, no. 1-2, pp. 194-201, 2011.

[6] M. Wang, J. Li, X. Li et al., "Magnetically and $\mathrm{pH}$ dual responsive dendrosomes for tumor accumulation enhanced folate-targeted hybrid drug delivery," Journal of Controlled Release, vol. 232, pp. 161-174, 2016.

[7] B. Tian, Q. Wang, Q. Su, W. Feng, and F. Li, "In vivo biodistribution and toxicity assessment of triplet-triplet annihilation-based upconversion nanocapsules," Biomaterials, vol. 112, pp. 10-19, 2017.

[8] Y. Xu, S. Asghar, H. Li et al., "Preparation of a paclitaxel-loaded cationic nanoemulsome and its biodistribution via direct intratumoral injection," Colloids and Surfaces B: Biointerfaces, vol. 142, pp. 81-88, 2016.

[9] L. Wan, X. Wang, W. Zhu et al., "Folate-polyethyleneimine functionalized mesoporous carbon nanoparticles for enhancing oral bioavailability of paclitaxel," International Journal of Pharmaceutics, vol. 484, no. 1-2, pp. 207-217, 2015.

[10] I. Chakraborty and P. K. Mascharak, "Mesoporous silica materials and nanoparticles as carriers for controlled and sitespecific delivery of gaseous signaling molecules," Microporous and Mesoporous Materials, vol. 234, pp. 409-419, 2016.

[11] J. Li, X. Miao, T. Chen, D. Ouyang, and Y. Zheng, "Preparation and characterization of pelletized solid dispersion of resveratrol with mesoporous silica microparticles to improve dissolution by fluid-bed coating techniques," Asian Journal of Pharmaceutical Sciences, vol. 11, no. 4, pp. 528-535, 2016.

[12] Y. Bi P, C. Wu N, and M. Xin, "Facile large-scale preparation of mesoporous silica microspheres with the assistance of sucrose and their drug loading and releasing properties," International Journal of Pharmaceutics, vol. 500, pp. 77-84, 2016.

[13] S. Zheng, Z. Jin, J. Han et al., "Preparation of HIFU-triggered tumor-targeted hyaluronic acid micelles for controlled drug release and enhanced cellular uptake," Colloids and Surfaces B: Biointerfaces, vol. 143, pp. 27-36, 2016.

[14] G. M. Krukemeyer, V. Krenm, and M. Jakobs, "Mitoxantroneiron oxide biodistribution in blood, tumor, spleen, and liver-magnetic nanoparticles in cancer treatment," Journal of Surgical Research, vol. 175, pp. 35-45, 2012.

[15] Q. Liu, R. Li T, Z. Zhu S et al., "Enhanced antitumor efficacy, biodistribution and penetration of docetaxel-loaded biodegradable nanoparticles," International Journal of Pharmaceutics, vol. 430, pp. 350-358, 2012.

[16] Y. L. Chen, M. C. Chang, C. Y. Huang et al., "Serous ovarian carcinoma patients with high alpha-folate receptor had reducing survival and cytotoxic chemo-response," Molecular Oncology, vol. 6, pp. 360-369, 2012.

[17] T. Chem J, T. Cheng W, and Y. Hung C, "Targeted folic acidPEG nanoparticles for noninvasive imaging of folate receptor by MRI," Journal of Biomedical Materials Reseach Part A, vol. 87, pp. 165-175, 2008.

[18] Q. Pan, Y. Lv, G. R. Williams et al., "Lactobionic acid and carboxymethyl chitosan functionalized graphene oxide nanocomposites as targeted anticancer drug delivery systems," Carbohydrate Polymers, vol. 151, pp. 812-820, 2016.

[19] M. Prabaharan, "Chitosan-based nanoparticles for tumortargeted drug delivery," International Journal of Biological Macromolecules, vol. 73, pp. 1313-1322, 2015. 
[20] M. Rajan, M. Murugan, and D. Ponnamma, "Poly-carboxylic acids functionalized chitosan nanocarriers for controlled and targeted anti-cancer drug deliver," Biomed Pharmacoth, vol. 83, pp. 201-211, 2016.

[21] S. Federici, F. Padovani, and M. Poli, "Energetics of surface confined ferritin during iron loading," Colloid Surface B, vol. 145, pp. 520-525, 2016.

[22] G. Fracasso, E. Falvo, and G. Colotti, "Selective delivery of doxorubicin by novel stimuli-sensitive nano-ferritins overcomes tumor refractoriness," Journal of Controlled Release, vol. 244, pp. 229-239, 2016.

[23] J.-Y. Lee, S.-J. Chung, H.-J. Cho, and D.-D. Kim, "Iodinated hyaluronic acid oligomer-based nanoassemblies for tumortargeted drug delivery and cancer imaging," Biomaterials, vol. 85, pp. 218-231, 2016.

[24] Y. Zhu, X. Wang, J. Chen et al., "Bioresponsive and fluorescent hyaluronic acid-iodixanol nanogels for targeted X-ray computed tomography imaging and chemotherapy of breast tumors," Journal of Controlled Release, vol. 244, pp. 229-239, 2016.

[25] Y. Zhang, J. Guo, X. Zhang L et al., "Antibody fragment-armed mesoporous silica nanoparticles for the targeted delivery of bevacizumab in ovarian cancer cells," International Journal of Pharmaceutics, vol. 496, pp. 1026-1033, 2015.

[26] C. F. Greineder, E. D. Hood, A. Yao et al., "Molecular engineering of high affinity single-chain antibody fragment for endothelial targeting of proteins and nanocarriers in rodents and humans," Journal of Controlled Release, vol. 226, pp. 229237, 2016.

[27] J. Ahn, Y. Miura, N. Yamada et al., "Antibody fragmentconjugated polymeric micelles incorporating platinum drugs for targeted therapy of pancreatic cancer," Biomaterials, vol. 39, pp. 23-30, 2015.

[28] J. Lu, Z. Li, J. I. Zink, and F. Tamanoi, "In vivo tumor suppression efficacy of mesoporous silica nanoparticles-based drug-delivery system: enhanced efficacy by folate modification," Nanomedicine, vol. 8, no. 2, pp. 212-220, 2012.

[29] W. Chen H, G. Luo F, Q. Lei et al., "Rational design of multifunctional magnetic mesoporous silica nanoparticle for tumortargeted magnetic resonance imaging and precise therapy," Biomaterials, vol. 76, pp. 87-101, 2016.

[30] N. Parker, M. J. Turk, E. Westrick, J. D. Lewis, P. S. Low, and C. P. Leamon, "Folate receptor expression in carcinomas and normal tissues determined by a quantitative radioligand binding assay," Analytical Biochemistry, vol. 338, no. 2, pp. 284-293, 2005.

[31] X. Du and J. He, "Fine-tuning of silica nanosphere structure by simple regulation of the volume ratio of cosolvents," Langmuir, vol. 26, no. 12, pp. 10057-10062, 2010.

[32] R. J. Ahern, J. P. Hanrahan, J. M. Tobin et al., "Comparison of feno?brate-mesoporous silica drug-loading processes for enhanced drug delivery," European Journal of Pharmaceutical Sciences, vol. 50, pp. 400-409, 2013.

[33] M. M. Zyada, M. E. Grawish, and H. M. E. Lsabaa, "Predictive value of cyclooxygenase- 2 and bcl 2 for cervical lymph node metastasis in mucoepidermoid carcinoma," Ann Diagn Pathol, vol. 13, pp. 313-321, 2009.

[34] A. A. Khan, A. M. Alanazi, M. Jabeen, I. Hassan, and M. A. Bhat, "Targeted nano-delivery of novel omega-3 conjugate against hepatocellular carcinoma: Regulating COX-2/bcl-2 expression in an animal model," Biomedicine \& Pharmacotherapy, vol. 81, pp. 394-401, 2016.
[35] Y. Ma, M. Sadoqi, and J. Shao, "Biodistribution of indocyanine green-loaded nanoparticles with surface modifications of PEG and folic acid," International Journal of Pharmaceutics, vol. 436, no. 1-2, pp. 25-31, 2012.

[36] M. Xie, H. Shi, Z. Li et al., "A multifunctional mesoporous silica nanocomposite for targeted delivery, controlled release of doxorubicin and bioimaging," Colloids and Surfaces B: Biointerfaces, vol. 110, pp. 138-147, 2013. 

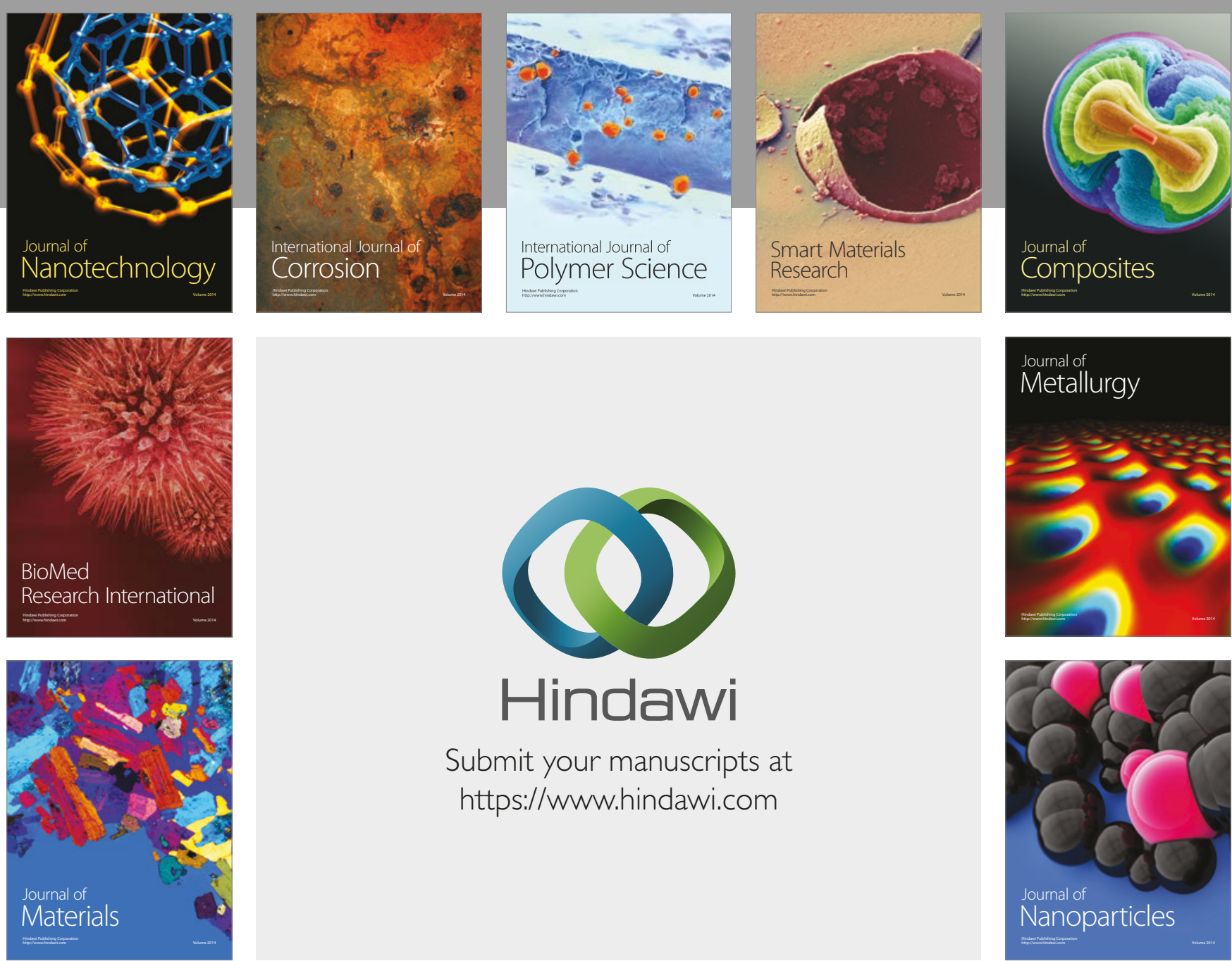

\section{Hindawi}

Submit your manuscripts at

https://www.hindawi.com
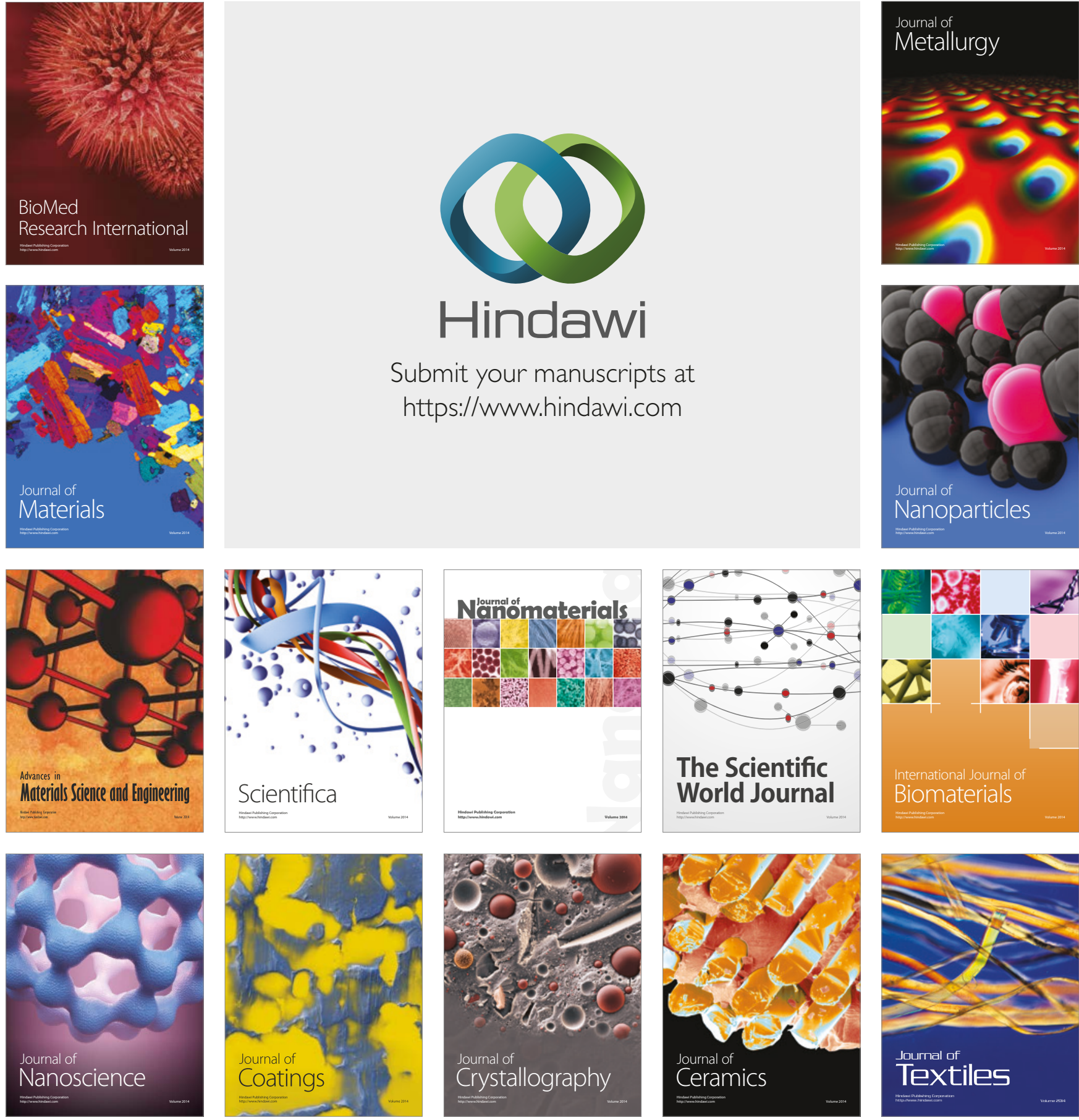

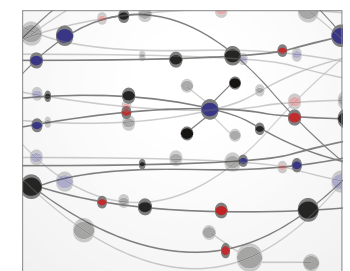

The Scientific World Journal
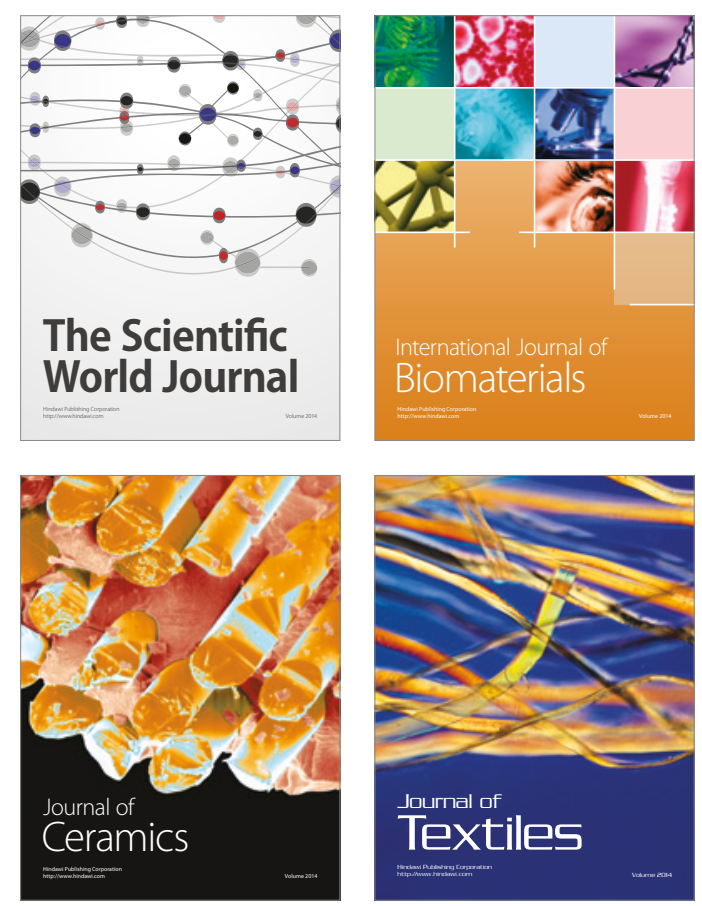